\title{
EVALUACIÓN DE UNA BACTERINA DE DOSIS ÚNICA CONTRA Mycoplasma hyopnemoniae EN PORCINOS DE MADRES NO VACUNADAS
}

\author{
Johana Flores J. ${ }^{1}$, Sonia Calle E. ${ }^{2,3}$, Néstor Falcón P.4, Marlon Torres A.

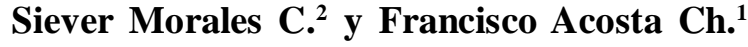

\section{Abstract}

The effect of a single dose bacterin against Mycoplasma hyopnemoniae on body weight gain, antibody titers, and degree of lung lesions in piglets from non-vaccinated dams reared in a pig farm with history of mycoplasmosis was evaluated. A total of 60 piglets of both sexes were distributed in a vaccinated and a control group. The bacterin was applied at 6 weeks of age. The frequency of seropositive animals and the antibody titers against $M$. hyopnemoniae were determined using serum samples collected at 3, 6, $10,12,16$, and 21 weeks of age. Body weight gain (g/day) was calculated from body weight at weaning (19 days) and at slaughter (140 days). Antibody levels were significantly higher at 10 and 13 weeks $(\mathrm{p}<0.05)$ in the vaccinated group, but similar from week 16 onwards, possibly due to the natural infection process in the control group. The level of lung lesions and number of affected animals was lower in the vaccinated group. It is concluded that the bacterin of a single dose had a positive effect against $M$. hyopnemoniae improving body weight gain.

Key words: Mycoplasma hyopnemoniae, bacterin, body weight gain, antibody titer, piglet

\section{Resumen}

Se evaluó el efecto de una bacterina contra Mycoplasma hyopnemoniae de dosis única sobre la ganancia de peso, títulos de anticuerpos y grado de lesión pulmonar de lechones procedentes de madres no vacunadas contra este patógeno y criados en una granja tecnificada con historia de micoplasmosis. Se utilizaron 60 lechones de ambos sexos distribuidos en un grupo vacunado y uno control. La bacterina se aplicó a las 6 semanas de edad. Se determinó la frecuencia de la seropositividad y el título de anticuerpos contra M. hyopnemoniae a través de muestras de suero colectados a las 3, 6, 10, 12, 16 y

\footnotetext{
${ }^{1}$ Práctica privada

${ }^{2}$ Laboratorio de Microbiología y Parasitología Veterinaria, FMV-UNMSM

${ }^{3}$ E-mail: calleson@ gmail.com

${ }^{4}$ Laboratorio de Medicina Veterinaria Preventiva, FMV-UNMSM

${ }^{5}$ Laboratorio de Producción Agropecuaria, FMV-UNMSM
} 
21 semanas de edad. La ganancia de peso ( $\mathrm{g} /$ día) se determinó a través del peso al destete (19 días) y el beneficio (140 días). El nivel de anticuerpos fue significativamente superior a las 10 y 12 semanas $(\mathrm{p}<0.05)$ en el grupo vacunado, pero similar a partir de las 16 semanas, posiblemente debido al proceso de infección natural en el grupo control. El grado de consolidación pulmonar y número de animales afectados fue menor en el grupo vacunado. Se concluye que la bacterina de dosis única tuvo un efecto positivo frente al $M$. hyopnemoniae en la mejora de la ganancia de peso.

Palabras clave: Mycoplasma hyopnemoniae, bacterina, ganancia de peso, título de anticuerpos, lechón

\section{INTRODUCCIÓN}

En la crianza porcina existe una serie de enfermedades que se tratan de controlar con la finalidad de obtener buenos parámetros productivos y mejores ingresos económicos. El Mycoplasma hyopneumoniae es uno de los agentes causantes de enfermedades respiratorias cuya presencia en la crianza porcina afecta la velocidad de crecimiento, reduce la eficienciaalimenticia(Hill et al.,1992; Copes et al., 1995), y baja la ganancia de peso (Calsamiglia, 1999), ocasionando lotes desiguales (Camacho y Calle, 2003). Por otro lado, ocasiona una baja mortalidad y elevada morbilidad (Blood et al., 1999).

Estudios realizados demuestran que los lechones están protegidos contra micoplasma por la inmunidad pasiva, hasta las 6 semanas de edad si proceden de madres no vacunadas y hasta 8 semanas si las madres son vacunadas (Armstrong, 1982). Ante estas circunstancias, se han desarrollado vacunas que brindan cierta protección al animal.

En la mayoría de granjas porcinas de Lima no se vacuna contra Mycoplasma hyopneumoniae, y si lo hacen, utilizan bacterinas de dos dosis y con diferentes esquemas de vacunación, en las cuales, se puede o no incluir la vacunación de madres gestantes. Actualmente se han desarrollado bacterinas de dosis única, que aparentemente tienen un efecto similar a las de dos dosis, con la ventaja de reducir el manejo y estrés sobre el animal (Kuhn, 2003).
El presente trabajo evaluó el efecto de una bacterina de dosis única de Mycoplasma hyopneumoniae en la ganancia de peso y en el título de anticuerpos durante el periodo productivo en porcinos procedentes de madres no vacunadas en una granja porcina tecnificada positiva a Mycoplasma hyopneumoniae.

\section{MATERIALes y Métodos}

El trabajo se realizó con muestras de suero procedentes de animales de una granja porcina de crianza tecnificada, positiva a Mycoplasma hyopnemoniae, localizada en la zona de Puente Piedra, Lima. La fase de campo se llevó a cabo de marzo a abril del 2003.

Se utilizaron 60 lechones divididos en dos grupos homogéneos y con similar cantidad de machos y hembras. Las madres eran animales sanos y con historia reproductiva de 2 a 3 partos. El grupo A fue vacunado a $\operatorname{los} 42$ días con una bacterina de Mycoplasma hyopnemoniae de dosis única $(2 \mathrm{ml})$, en la tabla del cuello por vía intramuscular. El grupo B no fue vacunado y quedó como control. Los lechones se encontraban en aparente buen estado de salud y siguieron el manejo rutinario y el programa sanitario de la granja.

Los lechones fueron pesados al destete (19 días) y al beneficio (149 días) y se calculó la ganancia de peso de este periodo. Además, se recolectaron muestras de sangre de 
la vena cava craneal a las $3,6,10,12,16$ y 21 semanas de edad. Los sueros se obtuvieron por centrifugación y se almacenaron en congelación $\left(-20{ }^{\circ} \mathrm{C}\right)$ hasta su análisis para la medición de los títulos de anticuerpos por medio de la prueba de ELISA Indirecta.

Durante el proceso de beneficio de los animales se revisaron los pulmones y se determinó el grado de lesión pulmonar, siguiendo los criterios señalados por Cisneros (2005).

El tamaño muestral se definió con la fórmula de diferencia de medias. Se empleó al análisis de varianza para determinar diferencias estadísticas en ganancia de peso por efecto de la vacunación, sexo y la interacción grupo por sexo. Así mismo, los títulos de anticuerpos se analizaron mediante la prueba de " $t$ " Student de Independencia y el grado de consolidación pulmonar mediante la prueba de "U de Mann-Whitney".

\section{Resultados}

Un animal de cada grupo murió durante el desarrollo del estudio, de allí que los resultados están referidos a 29 animales. La ganancia de peso obtenida entre el destete y el beneficio fue estadísticamente superior para el grupo vacunado $(\mathrm{p}<0.05)$. Así mismo, las diferencias debidas al sexo de los lechones y la interacción sexo y vacunación no fueron estadísticamente significativas (Cuadro 1).

En ambos grupos experimentales se pudo observar animales seropositivos (Cuadro 2). La media del título de anticuerpos a las 3 y 6 semanas de edad fue similar en los dos grupos, pero se observaron títulos más altos en el grupo vacunado a partir de las 6 semanas de edad por efecto de la vacunación (Cuadro 2, $\mathrm{p}<0.05)$. El título de anticuerpos de los animales del grupo control comienza a incrementarse a las 12 semanas, no habiendo diferencias estadísticas con el grupo vacunado a las 16 y 21 semanas de edad (Cuadro 2).
El grado de lesión pulmonar fue favorable para el grupo vacunado $(\mathrm{p}<0.05)$. Las lesiones observadas en el grupo vacunado se encontraron mayormente en las categorías 1 y 2, mientras que en el grupo control se encontraron en las categorías 1, 2, 3 y 5 (Fig. 1).

\section{Discusión}

La inmunización de los cerdos con una bacterina contra el micoplasma porcino en una zona donde este patógeno es prevaleciente, permite que los animales adquieran una inmunidad protectiva que impida que desarrollen la enfermedad y que obtengan mayores ganancias de peso, una edad más temprana para el beneficio y mejores tasas de conversión alimenticia (Muñoz et al., 1996). El grupo vacunado, al permanecer en un ambiente con animales infectados, estuvo propenso a contraer la enfermedad, desarrollando lesiones pulmonares, que a su vez, redujeron la eficiencia alimenticia y la ganancia de peso (Pointon et al., 1985).

El grupo vacunado obtuvo mayores ganancias de peso que el grupo control; sin embargo, no se encontraron diferencias estadísticas en el análisis de la ganancia de peso por efecto del sexo debido a la gran dispersión de los datos de cada grupo. Resultados similares fueron obtenidos por Valdivia (1999) al utilizar una vacuna de dos dosis, donde el grupo vacunado logró una ganancia de peso superior y donde los cerdos machos mostraron un comportamiento productivo más eficiente que las hembras.

La presencia de animales seropositivos a las tres semanas de edad indica que hubo una transferencia de anticuerpos maternales a los lechones, pese a que sus madres no estaban vacunadas contra $M$. hyopneumoniae. Esto es indicativo que había marranas infectadas durante el periodo de gestación y que el $M$. hyopneumoniae se encontraba presente en las instalaciones, 
Cuadro 1. Efecto de una bacterina de Mycoplasma hyopnemoniae de dosis única y del sexo en la ganancia de peso de lechones entre el destete y el beneficio

\begin{tabular}{llccc}
\hline Variable & & $\begin{array}{c}\text { Animales } \\
(\mathrm{n})\end{array}$ & $\begin{array}{c}\text { Ganancia de peso } \\
(\mathrm{g} / \text { día })\end{array}$ & $\begin{array}{c}\text { Desviación } \\
\text { estándar }\end{array}$ \\
\hline Grupo & & & & \\
& Vacunado & 29 & $90.8^{\mathrm{a}}$ & 10.0 \\
& No vacunado & 29 & $84.7^{\mathrm{b}}$ & 10.1 \\
\multirow{2}{*}{ Sexo } & & & & \\
& Hembra & 29 & $85.8^{\mathrm{a}}$ & 09.2 \\
& Macho & 29 & $89.7^{\mathrm{a}}$ & 11.3 \\
\hline
\end{tabular}

${ }^{a, b}$ Letras diferentes dentro de grupos indican diferencia estadística significativa $(p<0.05)$

Cuadro 2. Frecuencia de animales seropositivos y promedio del título de anticuerpos contra Mycoplasma hyopnemoniae en lechones que fueron vacunados a los 42 días con una bacterina de $M$. hyopnemoniae de dosis única

\begin{tabular}{cccccc}
\hline \multirow{2}{*}{$\begin{array}{c}\text { Edad } \\
\text { (semanas) }\end{array}$} & \multicolumn{2}{c}{$\begin{array}{c}\text { Vacunados } \\
(\%)\end{array}$} & & \multicolumn{2}{c}{$\begin{array}{c}\text { Control } \\
(\%)\end{array}$} \\
\cline { 2 - 3 } \cline { 5 - 6 } \cline { 5 - 6 } \cline { 5 - 6 } & Seropositivos & Título $^{1}$ & & Seropositivos & Título $^{1}$ \\
\hline 3 & 24.1 & $2.48^{\mathrm{a}}$ & & 10.3 & $2.42^{\mathrm{a}}$ \\
6 & 03.4 & $2.07^{\mathrm{a}}$ & & 0 & $1.95^{\mathrm{a}}$ \\
10 & 41.4 & $2.60^{\mathrm{a}}$ & & 03.4 & $0.96^{\mathrm{a}}$ \\
12 & 44.8 & $2.75^{\mathrm{a}}$ & & 10.3 & $1.43^{\mathrm{b}}$ \\
16 & 68.9 & $2.99^{\mathrm{a}}$ & & 06.2 & $2.75^{\mathrm{b}}$ \\
21 & 93.1 & $3.39^{\mathrm{a}}$ & & 86.2 & $3.17^{\mathrm{a}}$ \\
\hline
\end{tabular}

${ }^{a, b}$ Letras diferentes dentro de filas por efecto del título de anticuerpos indican diferencia estadística significativa $(p<0.05)$

${ }^{1}$ Título de anticuerpos del grupo experimental

favorecido por el sistema de manejo de la granja. Torres (2003), trabajando con lechones de madres no vacunadas encontró el $100 \%$ de animales seropositivos, relacionando este hecho a la gran actividad del patógeno dentro de la granja en estudio.

Los títulos de anticuerpos maternales fueron descendiendo hasta la décima semana de edad de los lechones. Estos resultados difieren con otros reportes donde se ha en- contrado que anticuerpos transmitidos por madres no vacunadas y expuestas naturalmente al patógeno persisten hasta la $6^{\mathrm{a}} \mathrm{u} 8^{\mathrm{a}}$ semana de edad (Calle et al., 2003). La bacterina permitió elevar los títulos de anticuerpos a partir de la décima semana, brindando inmunidad protectiva contra la enfermedad. Caso contrario ocurrió con los animales del grupo control que se infectaron entre las 10 y 12 semanas de edad, al descender los anticuerpos maternales. La fase 


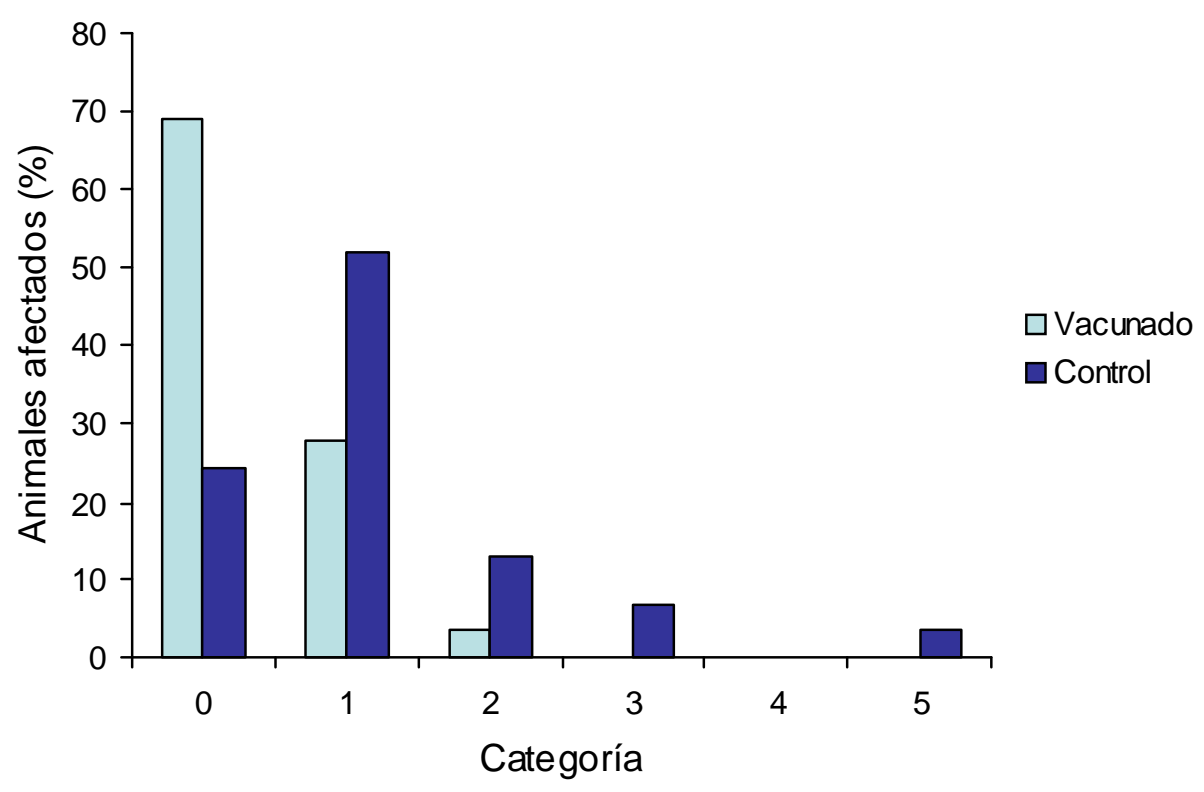

Figura 1. Distribución porcentual de lechones afectados con lesiones pulmonares según la categoría (porcentaje de consolidación) de lesión pulmonar (1: 0.1 a 11.0; 2: 11.1 a 21.0; 3: 21.1 a 31.0; 4: 31.1 a $41.0 ; 5: 41.1$ a $51.0 ; 6: 51.1$ a $100.0 \%$ )

infectiva coincidió con la etapa final de la recría y el pase de los animales a la etapa de engorde, lo que a su vez, representa un factor de estrés que puede provocar la susceptibilidad de los animales.

La presencia de anticuerpos vacunales a las 4 semanas de la vacunación, similar a lo reportado por Kuhn (2000), permite señalar que no hubo interferencia de anticuerpos maternales con la inmunidad producida por la bacterina, como se señala en otros trabajos (Thacker et al., 1998).

Se encontraron lesiones pulmonares en los animales del grupo vacunado, indicando la posible ocurrencia de animales infectados; sin embargo, la bacteriana impidió que el número de animales con lesiones fuera reducido y que el grado de consolidación pulmonar en estos animales sea bajo. Estos resultados coinciden con otros estudios donde se demostró las bondades de la vacunación contra $M$. hyopneumoniae (Estrada, 1996). Por otro lado, Noyes et al. (1990) determinaron que por cada incremento del $1 \%$ de neumonías se podría esperar una disminución de $1.5 \mathrm{~kg}$ en el peso corporal a los 180 días de edad, y Straw (1989) indicó que por cada $10 \%$ de incremento en lesiones pulmonares se producía una merma de $37 \mathrm{~g}$ diarios en la ganancia de peso.

\section{Conclusiones}

- Los animales inmunizados con la bacterina de dosis única contra Mycoplasma hyopneumoniae a las seis semanas de edad, obtuvieron una ganancia de peso a la edad de beneficio significativamente superior a los animales del grupo control.

- La aplicación de la bacteria redujo la frecuencia de ocurrencia y el grado de lesiones pulmonares.

- No sería necesario inmunizar las marranas gestantes en granjas positivas a $M$. hyopneumoniae si se vacuna a los lechones a las seis semanas de edad con bacterinas de dosis única. 


\section{Literatura Citada}

1. Armstrong, C.H. 1982. Neumonía por Micoplasma en cerdos. International Swine Update. Perspectivas mundiales sobre neumonía y disentería. Squibb 1: 6-8.

2. Blood, D.C.; O. Radostits; K. Hincheliff; C. Gay. 1999. Medicina Veterinaria. 9a ed. p 1195-1204. Ed. Interamericana Mc Graw Hill. Madrid.

3. Calsamiglia, M. 1999. Mycoplasma hyopneumoniae: Epidemiología y control. Ciencias Veterinarias. Disponible en: http://www.colvet.es/infovet/jun01/ ciencias_v/ articulo1.htm

4. Calle, S.; C. Camacho; M. Torres; N. Falcón; M. Cerón; E. Zacarías. 2003. Inmunidad natural e inducida contra Mycoplasma hyopneumoniae medida desde el nacimiento hasta la edad de mercado en cerdos bajo crianza intensiva. Mundo Avícola y Porcino 4: 48-49.

5. Camacho, C.; S. Calle. 2003. Neumonía enzoótica porcina. Mundo Avícola y Porcino 45: 48-50.

6. Cisneros, J.; S. Calle; M. Torres; N. Falcón; M. Morales; F. Acosta. 2005. Crecimiento de gorrinos provenientes de madres con y sin antecedentes de vacunación contra Mycoplasma hyopneumoniae. Rev. Inv. Vet. Peru 16: 129134.

7. Copes, J.; F. Nievas; R. Cerda; C. Perfumo. 1995. Aislamiento y caracterización de Mycoplasma sp. de pulmones de cerdos provenientes de mataderos. Analecta Veterinaria 15: 27-30.

8. Estrada, R. 1996. Neumonía por Mycoplasma y pleuropneumonía porcina. IV Seminario Internacional de Porcicultura. Lima. p 21-30.

9. Hill, MA.; A.B. Scheidt; R.F. Teclaw; L.K. Clark; K.E. Knox; M. Jordan. 1992. Association between growth indicators and volume of lesions in lung from pigs at slaughter. Am. J. Vet. Res. 53: 2221- 2223.
10. Kuhn, M. 2000. Duración de la inmunidad a Mycoplasma hyopneumoniae luego de una sola dosis de RespisureOne. Boletín Técnico Animal Health Group. Pfizer Inc. 6 p.

11. Kuhn, M. 2003. Respisure-One: Duración de inmunidad en cerdos jóvenes con anticuerpos maternales contra $M$. hyopneumoniae. Boletín Técnico Pfizer Salud Animal. New York. 8 p.

12. Muñoz, A.; F.J. Pallarés; G. Ramis. 1996. Use of general linear model to evaluate the effect of vaccination of swine with Stellamune Mycoplasma on zootechnical performance and financial gain. Proc. $14^{\text {th }}$ Ann. Cong. Int. Pig. Vet. Soc. Bologna, Italy. p 222.

13. Noyes, E.P.; D.A. Feeney; C. Pijoan. 1990. Comparison of the effect of pneumonia detected during lifetime with pneumonia detected at slaughter on growth in swine. J. Am. Vet. Med. Assoc. 197: 1025-1029.

14. Pointon, A.; M. Byrt; P. Heap. 1985. Effect of enzootic pneumoniae of pigs on growth performance. Austr. Vet. J. 62: 13-18.

15. Straw, B. 1989. Estimation of the cost of pneumonia in swine herds. J. Am. Vet. Med. Assoc. 195: 1702-1706.

16. Thacker, B.J; T. Boettcher; T. Anderson; E. Thacker; T. Young. 1998. The influence of passive immunity on serological responses to Mycoplasma hyopneumoniae vaccination. Proc. $15^{\text {th }}$ IPVS Congress. Birmingham 3: 154.

17. Torres, M. 2003. Determinación serológica de la infección con Mycoplasma hyopneumoniae en una granja de cerdos de crianza intensiva. Tesis de Médico Veterinario. Facultad de Medicina Veterinaria, Univ. Nacional Mayor de San Marcos. Lima. 41 p.

18. Valdivia, L. 1999. Respuesta a la vacunación contra neumonía enzoótica porcina en términos de producción en explotación intensiva de cerdos. Tesis de Médico Veterinario. Facultad de Medicina Veterinaria, Univ. Nacional Mayor de San Marcos. Lima. 28 p. 